\title{
Calcium, Magnesium and phosphate deficiency and their Effect on Clinical outcome in Critically Ill child
}

\author{
A.A.Abouamer ${ }^{1}$, D.R.Soliman ${ }^{1}$, H.M.Shaban ${ }^{2}$ and N.M.Anter ${ }^{2}$ \\ ${ }^{1}$ Pediatrics Dept., Faculty of Medicine, Benha Univ., Benha, Egypt \\ ${ }^{2}$ Clinical and Chemical Pahthology Dept., Faculty of Medicine, Benha Univ., Benha, Egypt \\ E-Mail:Nesreen23@gmail.com
}

\begin{abstract}
Critical illness may trigger an acute phase response which is associated with several metabolic derangements. These include hypocalcaemia, hypophosphatemia and hypomagnesaemia. To determine the incidence and associated risk factors of hypocalcaemia, hypomagnesaemia and hypophosphatemia that develop in critically ill children and their effect on their clinical outcome. 50 child enrolled in our study aged from 1month to 6 years admitted in pediatric intensive care unit in Benha University Hospital. Levels of serum calcium, magnesium and phosphate were measured during admission. The following variables were analyzed: age, gender, diagnosis on admission, clinical severity score on admission OFI (Organ Failure Index) and daily scores PELOD (Pediatric Logistic Organ Dysfunction), length of hospital stay and outcome were analyzed. Out of 50 patients, the frequency of Calcium deficiency was (64\%), magnesium deficiency (46\%), and phosphate deficiency $(57 \%)$ on admission. There was negative correlation between calcium level and PELOD ( $\mathrm{P}=0.048)$, OFI $(\mathrm{P}=0.001)$ and period of hospitalization $(\mathrm{P}=0.002)$. Patients with hypomagnesaemia on admission had higher PELOD score $(\mathrm{P}=0.008)$, higher $\mathrm{OFI}(\mathrm{P}=0.008)$,prolonged period of hospitalization $(\mathrm{P}=0.038)$ and was associated with hypokalemia $(\mathrm{P}<0.05)$.

Hypophosphatemia was associated with higher PELOD score $(\mathrm{P}=0.019)$ and increased period of hospitalization $(\mathrm{P}=0.012)$. Mortality rate increased in patients with hypocalcaemia $(\mathrm{P}=0.022)$ and also in patients with hypomagnesaemia $(\mathrm{P}=0.006)$. Deficiency of calcium, magnesium and phosphate were common among critically ill children and affected clinical outcome of patient.
\end{abstract}

Keywords: Hypocalcemia, Hypomagnesemia, Hypophosphatemia, Critical illness, Clinical outcome.

\section{Introduction}

Disorders of magnesium, calcium and phosphorus are common in patients admitted to intensive care units [1]. Routine monitoring and replacement of these ions are still underemphasized [2]. Most studies focus, on individual electrolytes without taking the interrelationship between specific deficits into account. Hypocalcaemia is a common derangement in both medical and surgical patients requiring intensive care. The reported prevalence varies significantly between studies due to differences in the population studied and the cutoff values used, with published figures ranging from $15 \%$ to $88 \%$ [3]. Magnesium is the fourth most common cation in the body and second most common intracellular cation after potassium, yet its deficiency is frequently overlooked. Various studies have reported the incidence of hypomagnesaemia up to $65 \%$ in critically ill-patients [4]. Hypophosphatemia in critical adult patients has a prevalence ranging from $20 \%$ to $40 \%$ [5]. Potential risk factors for hypophosphatemia reported in the literature, include refeeding, malnutrition, use of diuretics or steroids, catecholamines and antacids, excessive parenteral glucose administration, sepsis, and respiratory alkalosis [6] .

\section{Methods}

A prospective observational study included 50 patients aged between 1 month and 6 years old, who were hospitalized at Pediatric Intensive Care Unit, Benha University Pediatric department, during the period between Novamber 2015 and October2016 after ethical committee approval and written consent from the parents. We excluded patients with impaired renal functions, renal replacement, endocrinal disturbance, chronic diarrhea or chronic malnutrition as measured by weight below third percentile or clinical signs of rickets or kwashiorkor, patients received calcium, vitamin D or blood transfusion and total stay in PICU $<4$ hours.

The following data were collected: Age, sex, diagnosis, full clinical examination including; vital signs, and all system assessment. Weight measurement, Pediatric logistic organ dysfunction score (PELOD score) calculated on admission [7]. Organ failures were assessed according to Pediatric organ dysfunction criteria, presence of infection or sepsis were detected according to center for disease control and prevention [8]. Complete laboratory assessments including; CBC, CRP, arterial blood gases. Serum electrolytes, urea and creatinine, prothrombin time, partial thromboplastin time and total bilirubin level, alanine aminotransferase (ALT) and aspartate aminotransferase (AST),serum calcium, magnesium and phosphate. Electrolytes were classified as normal, hypo according to reference ranges obtained from Nelson text book of pediatrics [9]. Period of hospitalization and outcome (discharged or died) were recorded to test the risk factor of this metabolic derangement on admission and observe the course of electrolyte disturbance during stay. Data was analyzed using Statistical Package for Special Science software computer program version 16.0 (SPSS Inc., Chicago, Illinois, USA). Continuous variables were expressed as median, minimum, and maximum.

Categorical variables were expressed as number (??), percent (\%) and were compared using the chi-square test or Fisher's exact test, as indicated. Continuous variables were compared using Mann-Whitney test for abnormally 
distributed data and Student's t-test \& ANOVA for normally distributed data. Multivariate regression analysis was used to test the association between multiple quantitative and qualitative independent variables with the dependent variable. ?? Value less than or equal 0.05 was considered statistically significant.

\section{Results}

Our results revealed that $31(62 \%)$ females \& 19 (38\%) males, age ranged between 2 and 60 months with mean age $20.38 \pm 16.3$ months Table (1). Respiratory affection represented the majority of cases (56\%) followed by CNS causes (20\%) Table (2). GCS (Glascow Coma Score) ranged from (3-15),18 cases were full conscious ,18cases were mild drowsy,11cases were moderately drowsy, 2 cases were sever drowsy and only one case was comatosed, 32 out of 50 cases have no organ failure while 7 cases had single organ failure and 11 cases had multiple organ failure Table(1). According to PELOD score, 29 cases had no organ dysfunction while 3 cases had mild organ dysfunction and 9 cases had sever organ dysfunction. Out of 50 cases the incidence of hypocalcaemia was $64 \%$, hypomagnesaemia was $46 \%$ and hypophosphatemia was $54 \%$ Fig (1).The majority of CNS and respiratory cases had hypocalcaemia, incidence of hypomagnesaemia was more in cardiac and CNS diseases while incidence of hypophosphatemia was more in GIT and respiratory diseases(Table2). Out of 50 cases 11 died, 10 of them had hypocalcaemia ( $\mathrm{p}=0.022), 9$ had hypomagnesaemia $(\mathrm{p}=0.006)$ and 8 had hypophosphatemia $(\mathrm{p}=0.158)$ Table (3).

There was a statistically significant correlation between serum calcium $(\mathrm{Ca})$ level and serum sodium level (Na) $(\mathrm{P}=0.02), \mathrm{Hb}(\mathrm{P}=0.03)$, GCS $(\mathrm{P}=0.015)$, PELO D score $(\mathrm{P}=0.048), \mathrm{OFI}(\mathrm{P}=0.001)$ and period of hospitalization $(\mathrm{P}=0.002)$ (Table4). There was was a statistically significant correlation between magnesium level and $\mathrm{Hb}(\mathrm{P}=0.002)$, GCS $(\mathrm{P}=0.014)$, PELOD score $(\mathrm{P}=0.008)$, OFI $(\mathrm{P}=0.008)$ and period of hospitalization $(\mathrm{P}=0.038)$. There was a statistically significant correlation between serum phosphate level and age ( $\mathrm{P}=0.031)$, weight $(\mathrm{P}=0.036)$, BUN $(\mathrm{P}=0.012)$, PELOD $(\mathrm{P}=0.019)$ and period of hospitalization $(\mathrm{P}=0.012)($ Table4).

Table (1) Descriptive analysis of the study population on admission.

\begin{tabular}{lcc}
\hline Age & Median & $\mathbf{1 4 . 5}$ \\
& Mini & $\mathbf{2}$ months \\
& Max & $\mathbf{6 0}$ months \\
\hline Sex & Male & $19(38 \%)$ \\
Weight & Female & $31(62 \%)$ \\
& Median & 10 \\
Duration of stay (N=39) & Mini & 4 \\
& Max & 20 \\
PELOD (N=21) & Median & 10 \\
& Mini & 7 \\
No organ failure & Max & 30 \\
Single organ failure & Median & 11 \\
Multiple organ failure & Mini & 1 \\
Outcome & Max & 32 \\
& 32 & $(64 \%)$ \\
CRP & 7 & $(14 \%)$ \\
& 11 & $(22 \%)$ \\
& Died & $11(22 \%)$ \\
& Alive & $39(78 \%)$ \\
& Positive & $39(78 \%)$ \\
& Negative & $11(22 \%)$ \\
& Median & 12 \\
& Mini & 6 \\
& Max & 96 \\
\hline
\end{tabular}




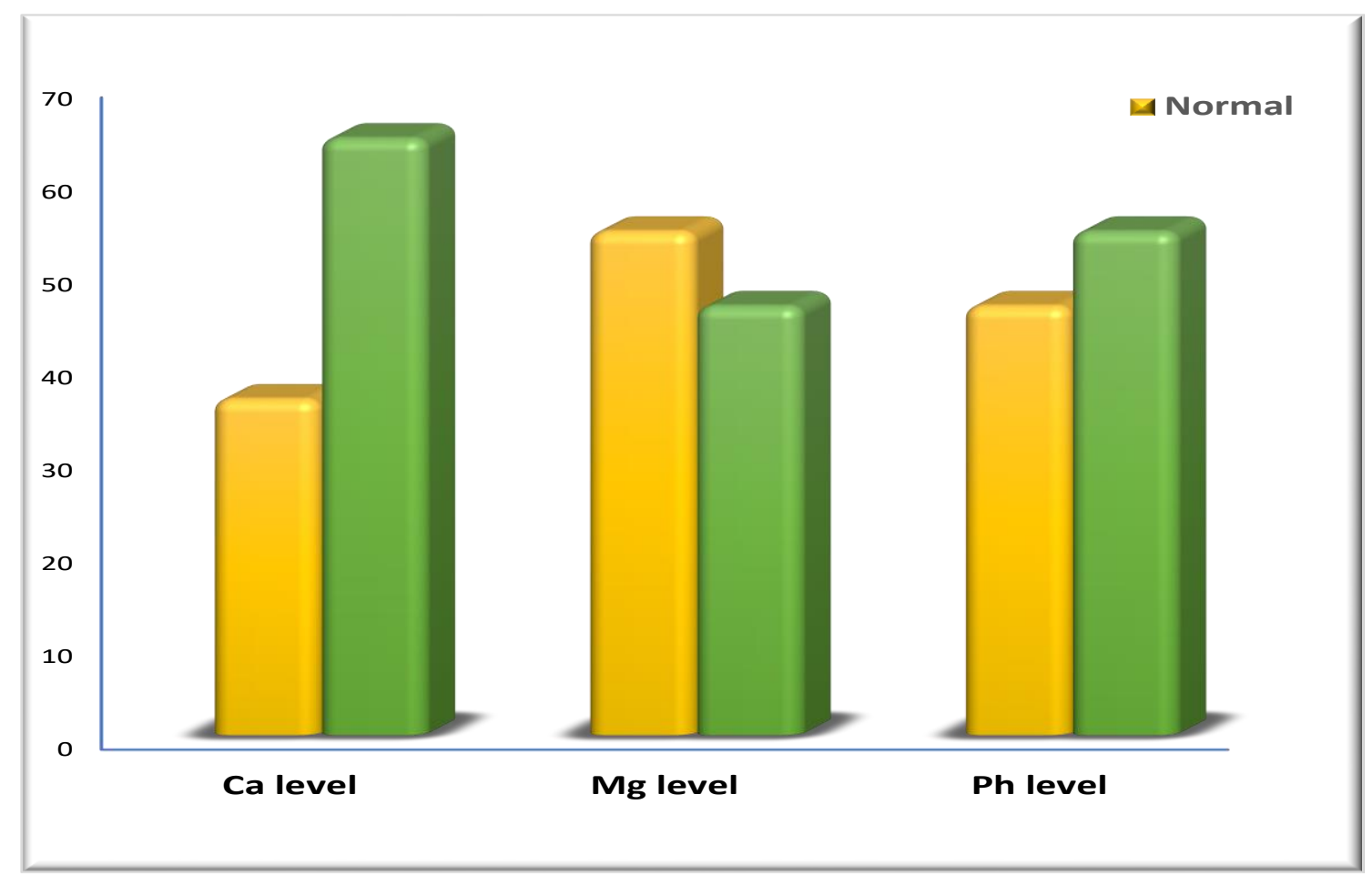

Fig (1) Serum $\mathrm{Ca}, \mathrm{Mg}$ and $\mathrm{Ph}$. levels of the cases group

Table (2) Occurrence\& incidence of Hypocalcaemia, Hypomagnesaemia \& Hypophosphatemia in admitted PICU patients with respect to their primary diagnosis.

\begin{tabular}{lccc}
\hline $\begin{array}{l}\text { Disease of } \\
\text { admission }\end{array}$ & Hypocalcaemia & Hypomagnesaemia & Hypophosphatemia \\
\hline Respiratory & 16 & 6 & 15 \\
$(\mathrm{~N}=28) 56 \%$ & $(57.1 \%)$ & $(21.4 \%)$ & $(53.6 \%)$ \\
Cardiac & 2 & 4 & 2 \\
$(\mathrm{~N}=4) 8 \%$ & $(50 \%)$ & $(100 \%)$ & $(50 \%)$ \\
CNS & 10 & 8 & 5 \\
$(\mathrm{~N}=10) 20 \%$ & $(100 \%)$ & $(80 \%)$ & $(50 \%)$ \\
GIT & 2 & 2 & 3 \\
$(\mathrm{~N}=4) 8 \%$ & $(50 \%)$ & $(50 \%)$ & $(75 \%)$ \\
Sepsis & 1 & 3 & 1 \\
$(\mathrm{~N}=3) 6 \%$ & $(33.3 \%)$ & $(100 \%)$ & $(33.3 \%)$ \\
Toxins & 1 & 0 & 1 \\
$(\mathrm{~N}=1) 2 \%$ & $(100 \%)$ & $(0.0 \%)$ & $(100 \%)$ \\
\hline
\end{tabular}

Table (3) Comparison between survivors \& cases before death as regards serum level of $\mathrm{Ca}, \mathrm{Mg} \& \mathrm{Ph}$.

\begin{tabular}{llllll}
\hline \multirow{2}{*}{ Serum level } & $\begin{array}{l}\text { Survivors } \\
\mathbf{N = 3 9}\end{array}$ & $\begin{array}{l}\text { Cases before death } \\
\mathbf{N = 1 1}\end{array}$ & X2 test & $\begin{array}{l}\text { P- } \\
\text { value }\end{array}$ \\
\hline \multirow{2}{*}{ Ca } & Normal & $17(43.6 \%)$ & $1(9.1 \%)$ & \multirow{2}{*}{4.4} & 0.022 \\
& Low & $22(56.4 \%)$ & $10(90.9 \%)$ & & $(\mathrm{S})$ \\
\multirow{2}{*}{$\mathbf{M g}$} & Normal & $25(64.1 \%)$ & $2(18.2 \%)$ & 0.006 \\
\multirow{2}{*}{$\mathbf{P h}$} & Low & $14(35.9 \%)$ & $9(81.8 \%)$ & 7.2 & $(\mathrm{HS})$ \\
& Normal & $20(51.3 \%)$ & $3(27.3 \%)$ & \multirow{2}{*}{1.99} & 0.158 \\
\hline
\end{tabular}


Table(4) Correlation between serum $\mathrm{Ca}, \mathrm{Mg}$ and $\mathrm{Ph}$. levels and the cases' parameters.

\begin{tabular}{|c|c|c|c|c|c|c|}
\hline & \multicolumn{2}{|c|}{$\mathrm{Ca}$} & \multicolumn{2}{|c|}{$\mathrm{Mg}$} & \multicolumn{2}{|c|}{$\mathrm{Ph}$} \\
\hline & $\mathrm{R}$ & $\mathrm{P}$ & $\mathrm{r}$ & $\mathrm{P}$ & $\mathrm{R}$ & $\mathrm{P}$ \\
\hline $\mathbf{C a}$ & & & 0.181 & 0.089 & 0.203 & 0.055 \\
\hline Mg & 0.181 & 0.089 & & & 0.078 & 0.463 \\
\hline $\mathbf{P h}$ & 0.203 & 0.055 & 0.078 & 0.463 & & \\
\hline Age & -0.062 & 0.67 & -0.121 & 0.40 & 0.305 & 0.031 \\
\hline HR & 0.193 & 0.18 & 0.022 & 0.88 & -0.169 & 0.24 \\
\hline Weigh & -0.073 & 0,61 & -0.055 & 0.71 & 0.298 & 0.036 \\
\hline $\mathbf{R R}$ & 0.222 & 0.12 & 0.150 & 0.30 & 0.128 & 0.374 \\
\hline Temperature & 0.300 & 0.03 & 0.271 & 0.06 & 0.149 & 0.30 \\
\hline WBCs & 0.102 & 0.48 & 0.254 & 0.07 & 0.191 & 0.183 \\
\hline HB & 0.302 & 0.03 & 0.430 & 0.002 & 0.174 & 0.23 \\
\hline Platelets & -0.047 & 0.74 & 0.089 & 0.57 & -0.066 & 0.65 \\
\hline $\mathbf{N a}$ & 0.325 & 0.02 & 0.040 & 0.79 & 0.074 & 0.61 \\
\hline $\mathbf{K}$ & 0,061 & 0.67 & 0.089 & 0.54 & -0.247 & 0.08 \\
\hline BUN & -0.203 & 0.16 & -0.073 & 0.61 & 0.351 & 0.012 \\
\hline Creatinine & -0.059 & 0.68 & -0.072 & 0.62 & -0.047 & 0.75 \\
\hline RBS & 0.070 & 0.63 & -0.102 & 0.48 & -0.204 & 0.16 \\
\hline PT & -0.072 & 0.63 & 0.107 & 0.46 & -0.050 & 0.73 \\
\hline PTT & -0.072 & 0.62 & -0.065 & 0.65 & 0.036 & 0.81 \\
\hline Bilrubin & -0.173 & 0.23 & 0.022 & 0.88 & -0.088 & 0.54 \\
\hline ALT & -0.135 & 0.35 & -0.065 & 0.66 & -0.125 & 0.39 \\
\hline $\mathbf{A S T}$ & -0.119 & 0.41 & -0.050 & 0.73 & -0.121 & 0.40 \\
\hline Albumin & 0.080 & 0.58 & 0.048 & 0.73 & 0.038 & 0.79 \\
\hline CRP & 0.165 & 0.253 & -0.139 & 0.337 & -0.069 & 0.634 \\
\hline GSC & 0.341 & 0.015 & 0.345 & 0.014 & 0.181 & 0.21 \\
\hline OFI & -0.467 & 0.001 & -0.372 & 0.008 & -0.265 & 0.63 \\
\hline PELOD & -0.282 & 0.048 & -0.317 & 0.008 & -0.332 & 0.019 \\
\hline Period of hospitalization & -0.471 & 0.002 & -0.333 & 0.038 & -0.397 & 0.012 \\
\hline
\end{tabular}

\section{Discussion}

The prevalence of hypocalcaemia in our study was $64 \%$ which was higher than the $34 \%$ reported by,[10]. Our study found that the majority of respiratory and all neurological diseases show hypocalcaemia, this agrees with a study done by [11] which revealed that $61 \%$ of cases admitted with neurological and $51 \%$ of cases admitted with respiratory diseases had hypocalcaemia. In contrast another study reported that chances of hypocalcaemia are higher if the underlying illness is renal or hematological [12].

We found in our study that mean value of $\mathrm{Na}$ level was lower among cases with hypocalcaemia than cases with normocalcaemia, this may be due to underlying disease or may be due to multiple electrolytes disturbance that may occur in critical children admitted in PICU [13].

In our study there was negative correlation between $\mathrm{Ca}$ level and PELOD score, this agrees with several studies which revealed hypocalcaemia was early event and was associated with organ dysfunction in children admitted to intensive care unit ${ }^{(11,14)}$. Also we found negative correlation between $\mathrm{Ca}$ and OFI, ${ }^{(15)}$ reported that hypocalcaemia is early predictive marker of multisystemic organ failure. Regarding to the period of hospitalization among survivors, we found that hypocalcaemia was associated with increased length of hospital stay [12,13]. In contrast ${ }^{(10)}$ found no association between hypocalcaemia and prolonged hospital stay.

The prevalence of hypomagnesaemia in our study was $46 \%$ which was relatively the same in comparison with [16] where $44 \%$ of their PICU patients had low magnesium at admission.In our study hypomagnesaemia was more pronounced in sepsis and neurologic diseases $[12,17]$

We found in our study significant association between hypomagnesaemia and hypokalemia, this may be due to underlying disorders that cause both magnesium and potassium loss such as vomiting, di arrhea, diuretics use or nasogastric suction. Moreover renal potassium losses are increased in hypomagnaesemic patients [17].

In our study $\mathrm{Mg}$ level was inversely correlated to PELOD and OFI. This is because hypomagnesaemia may cause severe and potential fetal complications and may lead to severe neuromuscular and cardiovascular clinical manifestations [18]. Also we found positive correlation between $\mathrm{Mg}$ level and GCS, this may be explained by the fact of hypomagnesemia in PICU was more in patients with convulsions and in patients with severe grades of altered sensorium [19]. Also we found that the patients with lower serum magnesium levels had longer ICU stay [20]. 
The prevalence of hypophosphatemia in our study was $57 \%$, lower than the $76.2 \%$ reported by [21]We observed that younger children were more affected due to their lower body reserve compared older ones ${ }^{\text {(22) }}$.Our study found that hypophosphatemia was more common among respiratory and GIT diseases which might be attributed to the fact that hypophosphatemia is known to lead to muscle weakness and hypotonia [22]. Also we found relation between hypophosphatemia and BUN which may be due to prolonged starvation and its effect on renal function.

Our study revealed negative correlation between level of phosphate and PELOD score. Hypophosphatemia leads to organ dysfunction and depletion of adenosine triphosphate (ATP) this would explain most of the derangement noted in cellular functions therefore, leads to tissue hypoxia and hence disruption of cellular function [23]. Our results agreed with the fact that hypophosphatemia increases the period of hospitalization, this might be explained by the effect of hypophosphatemia that can trigger myocardial dysfunction, low ATP for proper respiratory muscles contraction, leading to an increased need for ventilator support [22] while other studies reported that no significant correlation between $\mathrm{Ph}$ level and length of stay in the PICU $[21,24]$

In our study overall mortality rate was $(22 \%)$. There was a statistically significant difference between Ca level in survived and dead cases [12]. While [10] found no correlation between hypocalcemia and mortality. Also we found a highly statistically significant difference between magnesium level in survived and dead cases as mortality rate in hypomagnesaemic cases was $81.1 \%$ [20]. But [16] did not observe high mortality in hypomagnaesmic group.

Our study revealed no statistically significant difference between $\mathrm{Ph}$. level in survived and dead cases, which confirmed by other studies [21,25] While the study done by ${ }^{[22]}$ reported that cases with normal phosphorus level had better outcome $(\mathrm{P}=0.002)$.

\section{Conclusion}

Disorders of calcium, magnesium and phosphate are common in critically ill patients. Our study showed that serum concentrations of calcium, magnesium and phosphate are generally decreased in critically ill children. Calcium, magnesium and phosphorus are inversally correlated to the severity of disease and period of hospitalization. Also calcium and magnesium are inversally correlated to organ failure. Hypocalcaemia and hypomagnesaemia are associated to increased rate of mortality.

\section{References}

[1] L.I.Worthley, S.B.Baker,The essentials of calcium, magnesium and phosphate metabolism: part I. Physiology. Crit Care Resuscitation, Vol.4(4), PP.301-306, 2002.

[2] S.B.Baker, L.I.Worthley, The essentials of calcium, magnesium\& phosphate metabolism: part II.
Disorders. Crit Care Resuscitation, Vol.4(4), PP.307-315, 2002.

[3] Steele Tom, Kolamunnage-Dona Ruwanthi, Downey Colin, Toh Cheng-Hock, Welters Ingeborg. Assessment and clinical course of hypocalcaemia in critical illness. Crit Care, Vol.17(3), PP. 106-109, 2013.

[4] Mir Sadaqat Hassan Zafar, Javaid Iqbal Wani, Raiesa Karim, Mohammad Muzaffer Mir, Parvaiz Ahmad Koul. Significance of serum magnesium levels in critically ill-patients. Int J Appl Basic Med Res, Vol. 4(1), PP. 34-37, 2014.

[5] D.W.Miller, C.M.Slovis,Hypophosphatemia in the emergency department therapeutics. Am J Emergency Med, Vol.18, PP.457-46, 2000.

[6] F.S.De Menezes, H.P.Leite, J.Fernandez, S.G.Benzecry, Hypophosphatemia in critically ill children. Rev Hosp Clin Fac Med S Paulo 2004; 59:306-11.9-Thomas C, Fourrier F: Hypophosphore 'miesen re 'animation. Re 'animation, Vol. 12, PP.280-287, 2003.

[7] S.Leteurtre, A.Martinot, A.Duhamel, Validation of the paediatric logistic organ dysfunction (PELOD) score: prospective, observational, multicentre study. Lancet, Vol.362, PP.192-197, 2003.

[8] B.Goldstein, B.Giroir, A.Randolph, and the Members of the International Consensus Conference on Pediatric Sepsis. International pediatric sepsis consensus conference: definitions for sepsis and organ dysfunction in pediatrics. Pediatr Crit Care Med, Vol. 6, PP.2-8, 2005.

[9] F.Stanley,Reference Intervals for Laboratory Tests and Procedures. In: Kliegman RM, Behrman RE, Jenson HB, Stanton BF, editors. Nelson textbook of pediatrics, $19^{\text {th }}$ ed. Philadelphia, Pa: Saunders Elsevier,Vol. 70, PP.212-218, 2011.

[10] A. E.Beleidy, S. A. E.Sherbini, H. A. F.Elgebaly, A.Ahmed, Calcium, magnesium and phosphorus deficiency in critically ill children. Egypt Pediatr Assoc Gaz, Vol. 65, PP. 60-64, 2017.

[11] Neha Naik and Vithalrao Dandge,Role of calcium in critically ill children-Incidence of Hypocacemia in Pediatric Intensive Care Unit. Indian journal of applied research, Vol.25 (4), PP.409-12, 2003.

[12] S.C.Singhi, J.Singh, R.Parsad ,Hypo- and Hypermagnesemiain an indian pediatric intensive care unit. J Trop Pediatr;Vol. 49,PP.99-103,2003.

[13] Steele Tom, Kolamunnage-Dona Ruwanthi, Downey Colin, Toh Cheng-Hock, Welters Ingeborg. Assessment and clinical course of hypocalcaemia in critical illness. Crit Care, Vol.17(3), PP. 106-110, 2013.

[14] Calcida Rosa Barbosa, Heitor Pons Leite, Paulocesar Koch Noguiera, Wertner Brunow Decarvalho, Ionized hypocalcemia is an early event and is associated with organ dysfunction in children admitted to the intensive care unit. Journal of critical care,Vol.28(5)8, PP.10-815, 2013.

[15] Shigeyuki Kawa, Kendo Kiyosaw, Kenji Mukawa. Hypocalcemia $<7.5 \mathrm{mg} / \mathrm{dl}$ : Early predictive marker 
for multisystemic organ failure in sever necrotizing pancreatitis. American journal of Gastroentrology, Vol.95(4), PP.1096-97, 2000.

[16] A.Haque and A.F.Saleem, On admission hypomagnesemia in critically ill children :Risk factors and outcome. Indian J Pediatr, Vol. 76, PP.1227-30,2009.

[17] S.F.Dandinavar, D.Suma, V.H .Ratageri, P.K.Wari, Prevalance of hypomagnesemia in children admitted to intensive care unit and its correlation with patient outcome.Int J Contemp Pediatr, Vol.6, PP.462-7, 2019.

[18]Bent-Are Hansen and Qyvind Bruserud, Hypomagnesemia in critical ill patients Journalof Intensive care, Vol. 6, PP.21, 2018.

[19]Deshmukh CT,Rane SA,Gurav M.N. :Hypopmagnesemia in pediatric population in an intensive care unit J postgrad Med, Vol.46(3), p.179, 2000.

[20] S.A.J.Mousavi, S.Salimi, M.Rezai,Serum Magnesium Level Impact on the Outcome of Patients Admitted to the Intensive Care Unit. Tanaffos, Vol. 9, PP. 28-33,2010.

[21]F.S.De Menezes, H.P.Leite, J.Fernandez, S.G.Benzecry, Hypophosphatemia in critically ill children. Rev Hosp Clin Fac Med S Paulo 2004; 59:306-11.9-Thomas C, Fourrier F: Hypophosphore 'miesen re 'animation. Re 'animation, Vol. 12, PP.280-287, 2003.

[22] H.I.Rady, K.A.Khalek Mohamed , Prevalence and Risk Factors of Hypophosphatemia in Pediatric Intensive Care Unit. J Anesth Crit Care Open Access, Vol.1(6), PP.25-26, 2014.

[23]R.Subramanian and R. Khardori, Severe hypophosphatemia. Pathophysiologic implications, clinical presentations, and treatment. Medicine Baltimore , Vol.1:PP.1-8, 2000.

[24] J.F.Santana e Meneses, H.P.Leite, W.B.de Carvalho, E.Lopes Jr,Hypophosphatemia in critically ill children: prevalence and associated risk factors. Pediatr Crit Care, Vol.10, PP.234-8, 2009.

[25] S.K.Shah, M.Irshad, N.Gupta, S.K.Kabra, R.Lodha ,Hypophosphatemia in Critically Ill Children: Risk Factors, Outcome and Mechanism. The Indian Journal of Pediatrics. Nov1, Vol.83(12-13), PP.1379-85, 2016. 